\title{
A Racist Little Hat: The MSG Debate and American Culture
}

\author{
Written by Thomas Germain
}

(C) 2017 Germain. This is an open access article distributed under the terms of the Creative Commons Attribution License, which permits the user to copy, distribute, and transmit the work provided that the original author(s) and source are credited. 


\section{Acquired Tastes}

Stop for a moment and ask yourself what you know about monosodium glutamate. If you're anything like most Americans, your thoughts on the subject are probably simple: MSG is an artificial flavoring most often used with Chinese food, which should be avoided because it's bad for you and gives you headaches. If this is your thinking, you're not alone. For the past fifty years, this has been the conventional American understanding of MSG. But times change.

Recently, a vocal movement has sprung up that advocates for an end to the stigma surrounding MSG, as detailed in a Buzzfeed article by John Mahoney titled, "The Notorious MSG's Unlikely Formula For Success." Mahoney suggests that a new cultural context is emerging, spearheaded by a group of celebrity chefs who take the iconoclastic position that we should reintroduce MSG to our palates. They argue that beyond the merits of its delicious savory flavor, referred to as "umami," society's trepidations about the ingredient are based on research born out of stark racism and bad science which have perpetuated a myth about MSG's toxicity [1]. But the old guard isn't going quietly, and just as vocal as the pro-MSG camp are those who fear a change to the status quo.

Scientists and consumer advocates have argued since the late '6os that MSG causes health problems ranging from the unpleasant to the life threatening. The science is difficult to navigate, because for every study that finds that MSG is dangerous, another says it is perfectly safe. But those who argue against MSG insist that their challengers are nothing more than corporate shills, propagating misinformation to protect the bottom lines of huge corporations.

Whether or not the concerns of the anti-MSG camp are fact-based, their position is obfuscated by the racism highlighted in Mahoney's article. If we delve into the history of MSG, it is apparent the arguments against it are problematic. So problematic that a recent article arguing in favor of MSG can dismiss fifty years of hard science in a single sentence, saying "While nearly all the U.S. research that has suggested MSG is safe has been funded by companies that have a stake in MSG's success, researchers think the science that underlies them is sound" [2]. In three lines, the complicated scientific argument about MSG's safety is brushed away. It could be argued that this reasoning is the result of an industry-funded propaganda campaign, but the history of MSG is far more complex than corporate greed.

MSG's beginnings were innocent enough. When MSG was first synthesized in Japan it quickly dominated the market due to its flavor-enhancing capacity and a scientific connotation that made it appear hygienic. It spread across Asia and found similar success in the United States, but things changed when Chairman Mao seized control of China in 1949. Suddenly, our perception of the Chinese changed, and they were more than just foreign and confusing. There was something legitimately scary about them in 
the eyes of mid-century Americans: they were communists. The association between Chinese food and health problems was an easy connection for Americans to make because the Chinese were threatening. In order for Americans to justify their fears, they latched onto MSG. Moreover, "scientific" was no longer an appealing attribute; it made MSG seem strange. Just like the Chinese.

In the ' 60 s and '70s, Americans turned away from MSG because of negative feelings about the Chinese; and in the same way, the modern push to reintroduce MSG to polite society is as much about a desire to be anti-racist as it is about MSG's effects on our health. What we are left with is an argument so polarized that thoughtful consideration is not taking place.

The nature of the debate raises questions more interesting than the technical issue of safety. While your feelings about MSG may be straightforward, its story is not. MSG says a lot about our culture, but to appreciate this requires a holistic approach. We must understand history and prejudice, and parse a controversial body of scientific work that is complicated both by personal bias and corporate propaganda. Only then can we comprehend the subtext of the statement we are making when we decide whether or not to tell our waiters, "No MSG."

\section{Finger Lickin' Good}

The fact is that much of what we think about MSG is a misconception. There is nothing inherently Chinese about it, and it is not necessarily as "artificial" as one might assume. According to the Food and Drug Administration, MSG, or monosodium glutamate, is a food additive most commonly produced by fermenting organic material such as starch, beets, or molasses. It is a pervasive ingredient in cooking around the world, particularly in East Asia, but MSG is also commonly used by manufacturers of processed foods such as Doritos and fast food purveyors like KFC. Yet, in the minds of Americans, it is inextricably tied to Chinese food. Chinese takeout menus across the country are often branded with the proud declaration that their food is free of MSG, seemingly with the intention of calming the minds of would-be restaurant patrons, and assuring them that the meal they are about to consume is safe and free from the devilish ingredient. Colonel Sanders, however, feels no need to reassure his customers. How did we get to this point?

The chemical was first isolated by the Japanese chemist Kikunae Ikeda in 1908, who was intrigued by the satisfying flavor of the sea kelp that is a staple of Japanese cooking. The chemical he produced, monosodium glutamate, had a distinctive taste that Ikeda referred to as "umami," (Japanese for "delicious") and thereafter, the company Ajinomoto was founded to produce and market the ingredient. 
MSG quickly rose to prominence across Asia. According to Jordan Sand, professor of Japanese History at Georgetown University, at the turn of the century a "new domesticity was emerging as a critical component of class identity for the elite," and Ajinomoto tapped into this sentiment by presenting its product as hygienic, scientific, and efficient [3]. For Japanese housewives, a desire to identify themselves as enlightened, modern, and responsible laid the foundation for Ajinomoto's success, and made picking MSG an easy decision when it was presented in a way that equated it with these values. According to Sand, "Ajinomoto marketers appealed to the Japanese housewife's newfound sense of herself as a culinary professional and of her kitchen as a laboratory" [3]. From the beginning, MSG's success was tied as much to flavor as it was to cultural identity, a factor that would be just as significant in its downfall.

In a matter of decades, MSG dominated the Japanese diet. Sand describes how it soon spread to other countries such as Taiwan and, notably, China, and became indispensable at each stop along the way. By the 1930s MSG had crossed the Pacific and landed in the United States. Much of the MSG used in the United States found its way here due to the taste preferences of Chinese immigrants. Chinese restaurants exploded in popularity in the United States during World War II, Sand suggests, in part due to American's sympathy for the horrors of the Japanese invasion of China [3]. Once again, MSG made its way to our plates through choices we made with our superegos as much as our tongues.

However, the real surge in American consumption of MSG came primarily from the supermarket, as manufacturers of prepackaged foods recognized the chemical's flavorenhancing capacity, and Americans started buying pure MSG for home cooking under the brand name "Ac'cent" in 1947 [3]. In the coming decades, Americans would make an indelible connection between MSG and the Chinese, but for now they were unwittingly consuming it in mass quantities, in everything from Campbell's soup to baby food to chop suey. In the first half of the $20^{\text {th }}$ century, MSG was still nothing more sinister than what the 1953 edition of The Joy of Cooking would later call "the mysterious 'white powder' of the Orient" [3]. But a lot of things changed during the Cold War, and our mostly unconscious love affair with the food additive was one of them.

\section{A Bizarre and Excessive Syndrome}

In 1968, Dr. Robert Ho Man Kwok, a then recent Chinese immigrant, wrote a letter to the editors of the New England Journal of Medicine (NEJM). Dr. Kwok complained of a strange set of symptoms he experienced when he ate at "certain Chinese food restaurants," symptoms he did not experience when he ate back in China or in his own home cooking [4]. He described "numbness at the back of the neck, gradually radiating to both arms and the back, and general weakness and palpitation." Dr. Kwok speculated about a few potential culprits for these maladies, with MSG among them. The NEJM 
gave his letter the amusing title "Chinese Restaurant Syndrome," but Americans failed to see the humor. Soon, countless others were writing the offices of the NEJM complaining of similar experiences with Chinese food [5]. Unbeknownst to Dr. Kwok, his letter had shined a prejudiced spotlight on Chinese cooking that shapes our thinking to this day.

What is perhaps the most interesting aspect of Chinese Restaurant Syndrome (CRS) is the frantic tone that surrounded it, which historian Ian Mosby described as an "obviously racialized discourse that framed much of the scientific, medical and popular discussion surrounding the condition" [5]. A disease like CRS might seem questionable in other circumstances. In hindsight, why was it so easy to believe that one particular type of cuisine would make you sick, and why hadn't anyone noticed this before? Why didn't these restaurants go out of business if the effects of their food were so dire? It seems most people were uninterested in these questions. Instead of responding with scrutiny, Americans went looking for an explanation for CRS, because it confirmed a pre-existing unease regarding the Chinese.

Letters to the NEJM contributed to an ever-growing list of symptoms attributed to the horrors of Chinese cooking, including cold sweats, "tightening of the face," and a particularly eloquently described "Chinese headache" [5]. One sufferer wrote that he experienced the syndrome in the context of other ethnic foods, including "Japanese Teriyaki, [and] also, alas, after eating matzoh ball and split pea soups in a Kosher delicatessen." Looking back, this quote takes on an interesting significance. At the time, it had not been officially declared that MSG was the cause of CRS; all the writer of this letter knew was that when he ate at an ethnic restaurant, he felt sick. Ten years later, an MSG related study would point out that regardless of the contents of their meals, "Many people do experience unpleasant symptoms after eating, and particularly after eating food associated with a different culture" [5]. Perhaps it wasn't MSG that was causing CRS; it was the apprehensions about other ethnicities.

Still, studies in 1969 demonstrated a link between CRS and MSG, and fears about the food additive seeped from the pages of medical journals out into the public discourse. According to Mosby, a 1969 New York Times Article entitled "In Hong Kong it's Dog or Snake at Lunch Now," detailed the consumption of illegal meats in Hong Kong, which were being hidden on menus under deceitful code names. The article culminated with quotes from Hong Kong restaurateurs describing their growing concern over the American MSG debate [5]. For The Times, there was a clear connection to be made between the strange and underhanded use of dog meat and the use of MSG. The Times didn't make this explicit, but the implication is clear: in the same way the sneaky Chinese might trick you into eating dog, they were just as likely to hide MSG into your food. The New York City Health Department wasted no time getting involved, and a letter "demanding that MSG be used 'sparingly when preparing food' was sent out in English and Chinese to both manufacturers and vendors of Chinese food" [5]. The letter was not sent to non-Chinese restaurants, nor was it sent to American food manufacturers. Though MSG was used in other contexts, in the eyes of the Health Department, the "MSG problem" was strictly Chinese. 
Kwok's letter had clearly struck a chord, and as Mosby put it, "debates over the syndrome's causes and existence brought to the surface and, in a way, granted a renewed medical legitimacy to a number of long-held assumptions about the strangely 'exotic,' 'bizarre,' and 'excessive' practices associated with Chinese culture" [5]. Americans were primed to believe in this supposed disease because of their wariness of Chinese immigrants. MSG was just a racist little hat to hang on our preconceived notions about the Chinese.

\section{A Bizarre and Excessive Syndrome}

Eager to find a scientific underpinning for Dr. Kwok's symptoms, in 1969 pharmacologist Herbert Schaumburg and neurologist Robert Byck published a study that showed a "causal link" between MSG, headaches, and CRS, which not only cemented the existence of CRS in the minds of Americans, but also confirmed that MSG triggered it [6]. In the years following, a flurry of other researchers followed in their footsteps, but Schaumburg and his colleagues made one observation that many of their followers did not, namely that MSG was widely used in other American food products.

Why then had it taken so long to discover the syndrome, and why weren't complaints being made about the headaches caused by MSG-laden Campbell's soup or other products? This issue was largely ignored because, as Ian Mosby reported, researchers explained that MSG didn't cause CRS in other contexts "because of 'excessive' and 'bizarre' cooking practices in [Chinese] restaurants" [5]. These assumptions were indicative of the thinking that surrounded the entire controversy. Americans were quick to jump on board with CRS because the idea that there was something about Chinese cooking that would make you sick was easy to believe. Food historian Harvey Levenstein argues that fears about MSG are simply another example of the "ever present fears of what was going on in the inscrutable Chinese kitchens" [5]. Perhaps it wasn't the MSG that was causing Americans' headaches; it was the Chinese. Or perhaps, as some argue, there weren't any headaches at all. Almost immediately, competing studies were published that disputed the existence of CRS altogether, and pointed to obvious bias and methodological flaws in CRS research [5].

In 1969 an interesting divergence took place in the discussion of MSG. For most people, the concerns about MSG revolved around headaches and symptoms that more or less resembled CRS. Accordingly, Schaumburg and others continued to do a great deal of research on CRS, and in turn competitors continued to do research that contested their findings. But just after the initial batch of studies, a new player entered the arena and took his research in a new direction.

That same year, Washington University's Dr. John Olney published an article in Science which found that mice dosed with MSG developed brain lesions, stunted 
skeletal growth, obesity, and female sterility [7]. A few years later Olney published a new study that found similar defects in infant primates [7]. These effects were far more serious than "tingling." In the '7os he enlisted the help of America's consumer-advocate sweetheart, Ralph Nader. Together they led a charge to get the Food and Drug Administration to ban MSG [5].

But the farthest that federal regulators were willing to go was to suggest that MSG was "fit for human consumption but not necessarily by infants" [5]. Mosby argues that "this seemingly contradictory ruling reflected the tenuous middle-ground that regulatory agencies and other oversight bodies would continue to walk throughout the 1970s between the interests of consumers and the food industry" [5]. It appears the FDA was hedging its bets, and such an unclear ruling makes their motivation suspect. Certainly, if they wanted a definitive answer they could have done more research. This is enough to make one think that the fix was in, and Olney would indeed go on to make that argument. But this is not to say that the FDA wasn't basing its ruling on hard science. Many argued that the conclusions Olney reached through animal testing were not applicable to the way humans process MSG [5]. What's more, some studies replicating Olney's work and found contradictory results, though the legitimacy of these follow-up studies has been called in question [8].

But after a very public battle, Olney and Nader were unsuccessful, and to this day the FDA has never removed MSG from its list of products that are "Generally Recognized as Safe.” The purveyors of MSG had won, at least from a regulatory standpoint. Ralph Nader would move on to bigger and better failures, but Olney continued to fight against MSG for the rest of his career. The battle to ban MSG carries on to this day, and those in the anti-MSG camp have much to say about the science that contradicts their claims.

In 1999, Adrienne Samuels published an article on MSG research with the suggestive subtitle A Study in Suppression of Information. She provides evidence that the majority of studies that argue in favor of MSG, particularly those used in the FDA's ruling, have been funded by the Glutamate Association, a cagey organization that Samuels suggests was founded by Ajinomoto "to defend the safety of its product, and [unleash] a public relations campaign" [8]. One doesn't need to be an expert to question the findings of industry-funded studies, and Samuels' allegations of malfeasance do not stop there.

In her article, Samuels published a letter by Olney which states that since the " 70 s the FDA has been colluding with the MSG industry, citing studies which use obviously flawed, intentionally misleading, and even fabricated data, and engaging in outright conspiracy to hide the life-threatening reality of MSG from the public [8]. The accusations of cover-up and conspiracy Samuels highlights are as heinous as they are easy to believe. Olney's assertion, that the FDA is looking out for the interests of the food industry, not for our health, seems like a logical conclusion. Furthermore, Ajinomoto has been convicted of well documented anti-consumer conspiracies in the past. In the 90s, Ajinomoto was embroiled in a price fixing scheme which served as the inspiration for the Matt Damon film The Informant, during which they colluded with executives from other multinational food conglomerates like Archer-Daniels-Midland, 
and executives were secretly recorded saying things to each other like "our customers are our enemies" (Conner 5).

But while some argue that every scientist who finds evidence in favor of MSG's safety is a corporate shill, according to Samuel Wang, associate professor of molecular biology and neuroscience at Princeton University, this is not the case. Wang argues the chemical categorically does not cause brain damage, and contends that Ajinomoto is "not in a position to send tentacles into the entire scientific establishment and bend all our minds to its will" [1]. We need to weigh these claims for ourselves, because for the time being the FDA is not going to do that job for us. But it is a question worth addressing, considering the fact that the average American consumes over half a gram of added MSG per day (U.S. Food and Drug Administration).

\section{IV. "Our Customers Are Our Enemies"}

It's clear that racial biases sparked the original medical concerns over MSG. These prejudices encouraged anti-MSG sentiment, and many doctors and scientists reached conclusions that crumble in the face of scrutiny. Chinese Restaurant Syndrome is ridiculous in retrospect; it's absurd to think that that MSG would cause headaches only in the hands of Chinese cooks. But confusing the issue, the same racist hysteria that caught Americans' attention in the first place led to the work of scientists like Olney, whose work is both more frightening and less tainted by racist undertones.

It's reasonable to be skeptical of the FDA, and to assume that it doesn't exist purely to champion public health, but instead to balance the interest of public health with the economic well-being of corporations. And as consumers, it behooves us to be incredulous towards these giant corporations, particularly those that have been convicted of criminal charges. Nonetheless, it's fascinating that after 50 years of research, this scientific medical issue hasn't been resolved in a clear way. Maybe the fact that Olney's findings have yet to be proven definitively suggests that there is no problem, because it's hard to imagine that there are serious health issues that could have been ignored and unrecognized for this long. This isn't to say there is nothing to worry about, but it doesn't lend credence to Olney's contention that the wool is being pulled over our eyes by malevolent corporations.

To go a step further, maybe there were never any headaches in the first place. Maybe the whole story is little more than hysteria, or perhaps the headaches exist but are psychosomatic. One could point to many studies that cast serious doubts on the connection between MSG and CRS symptoms in general [2].

The new cultural understanding called for by the celebrity chefs in Mahoney's article is worth considering, and we should stop to think what it means when we shun MSG. Food 
is inherent to the preservation of culture, and it is central to building and maintaining communities. Therefore, when we demand that ethnic foods conform to our own cultural standards, we are reinforcing the exclusion of immigrants from mainstream society. Asking your waiter not to put MSG in your wonton soup may be a subconsciously aggressive act. If, wrongly or not, we assume that MSG is a significant part of Chinese culture, by rejecting it we may be making the unintentional statement that we want the Chinese to keep their culture to themselves. In a way, we are making a value judgment about the "otherness" of the Chinese, and denying their shared humanity. However, if the health concerns that MSG's detractors bring up are real, this may be an unfortunate necessity. Things are not so cut and dry, and it seems hasty to embrace MSG without definitive proof of its safety.

I'm not qualified to make a ruling about the safety of MSG. This would require an authority that could come only from medical and scientific training, but the FDA isn't going to make this judgment call for us. Here we have a beautiful example of the need for critical thinking. To that end, I've done a little of my own. I decided to do an unscientific experiment. I went to an Asian market near my apartment and bought myself a bottle of Ajinomoto-brand MSG. It looks a lot like salt, and it isn't quite so scary when you hold it in your hands. I ordered some Chinese take-out to go with it. I told the waiter "no MSG," but when I got home I added my own. It was delicious, and the headaches never came. You should try it. Just don't have too much.

\section{References}

1. Mahoney, John. BuzzFeed. "The Notorious MSG's Unlikely Formula For Success.” BuzzFeed. N.p.,16 Aug. 2013. Web. 24 Mar. 2016.

2. Barry-Jester, Anna Maria. "How MSG Got A Bad Rap: Flawed Science And Xenophobia.” FiveThirtyEight. N.p, 8 Jan. 2016. Web. 30 Mar. 2016.

3. Sand, Jordan. "A Short History of MSG: Good Science, Bad Science, and Taste Cultures.” Gastronomica 5.4 (2005): 38-49. Print.

4. Kwok, Robert Ho Man. "Chinese-Restaurant Syndrome.” New England Journal of Medicine 278.14 (1968): 796-796. Taylor and Francis+NEJM. Web.

5. Mosby, Ian. “That Won-Ton Soup Headache': The Chinese Restaurant Syndrome, MSG and the Making of American Food, 1968-1980 (English)." Le syndrome du restaurant chinois, le GMS et la fabrication de l'alimentation américaine, 1968-1980 (French) 22.1 (2009): 133-151. Print.

6. Schaumburg, Herbert H., et Al. "Monosodium L-Glutamate: Its Pharmacology and Role in the Chinese Restaurant Syndrome.” Science. 163 (1969): 826-8. Print 
7. Olney, J.W. (1993, April) Prepared statement for the public meeting (April 1993) pertaining to adverse reactions to monosodium glutamate (MSG). Presented at a public meeting conducted by the Federation of American Societies for Experimental Biology (FASEB), Bethesda, MD.

8. Samuels, Adrienne. "The Toxicity/Safety of Processed Free Glutamic Acid (MSG): A Study in Suppression of Information." Accountability in Research: Policies \& Quality Assurance 6.4 (1999): 257. Print.

Connor, John M. "'Our Customers Are Our Enemies': The Lysine Cartel of 1992-1995." Review of Industrial Organization. 18 (2001): 5-21. Print 